\title{
LYMPHADENOPATHY - AN UNUSUAL CLINICAL FEATURE OF KALA-AZAR
}

\author{
MD. SHAFIQUL BARI ${ }^{1}$, MIRZA AZIZUL HOQUE ${ }^{2}, \mathrm{KFM} \mathrm{AYAZ}^{3}$, AFSANA BEGUM ${ }^{4}$, RUBINA \\ YASMIN $^{5}$, MD. BILLAL ALAM ${ }^{6}$, HAM NAZMUL AHASAN $^{7}$
}

\begin{abstract}
:
We report a 25-year-old man presenting with fever and weight loss for the six months along with anemia, hepatosplenomegaly and axillary lymphadenopathy. Laboratory investigations showed pancytopenia. Bone marrow and splenic aspiration was inconclusive, lymph node biopsy revealed $L D$ bodies thus confirming visceral leishmaniasis. The case high lights the need of accepting lymph nodes as a site for diagnosing kala-azar and kala-azar lymphadenopathy is not as elusive as we think.
\end{abstract}

\section{Introduction:}

The annual estimate for the incidence and prevalence of kala-azar cases worldwide is 0.5 million and 2.5 million respectively. Surveillance data show an increasing trend in incidence since 1995 . Of these, $90 \%$ of the confirmed cases occur in Indian subcontinent. Lymphadenopathy which is a certainly unusual feature of kala-azar but still has been reported in some series. ${ }^{1}$ We report here an unusual case of kala-azar with lymphadenopathy in which fine needle aspiration from lymph node revealed histiocytes stuffed with $\mathrm{LD}$ bodies.

\section{Case report:}

A 25-year-old man from Gopalganj, presented to Dhaka Medical College \& Hospital with the complaints of fever and weight loss for months. Fever was low grade, irregular without any periodicity and failed to respond to multiple courses of antibiotics.

He was moderately anaemic and weighed $41 \mathrm{Kg}$. Axillary lymph nodes were palpable on both sides which were discrete, nontender, firm in consistency. He had also hepatosplenomegaly. Liver was palpable $4 \mathrm{~cm}$ below the right costal margin and it was nontender, firm in consistency, smoothed surface and with sharp margin. Spleen was palpable $16 \mathrm{~cm}$ from the left costal margin which was nontender and firm in consistency. He had no jaundice, oedema or other stigmata of chronic liver disease.
Laboratory investigations revealed WBC count 3000/ $\mathrm{mm}^{3}$ with $47 \%$ neutrophils and $48 \%$ lymphocytes. Platelet count was $100,000 / \mathrm{mm}^{3}$. ESR was 112 in the $1^{\text {st }}$ hour. Peripheral blood film did not show malarial parasites. Mantoux test was negative and chest x-ray revealed no abnormality. Ultra sonogram of abdomen showed hepatosplenomegaly. Endoscopy of upper GIT showed duodenal ulcer disease. Titre of direct agglutination test was $>1: 6400$. Aspirates of bone marrow showed secondary reactive changes. Splenic aspirates did not show any Leishmania Donovan bodies. FNAC of axillary lymph node showed histiocytes stuffed with Leishman Donovan bodies.

The patient was treated with injection sodium stibogluconate intravenously at a dose of $20 \mathrm{mg} / \mathrm{kg}$ for 20 days. Fever subsided at the $7^{\text {th }}$ day of therapy. Spleen showed regression of size and lymphadenopathy disappeared at the $3^{\text {rd }}$ week of therapy.

\section{Discussion:}

Visceral leishmaniasis presenting with fever and hepatoslenomegaly is a common phenomenon in Bangladesh. Identification of this disease is commonly done by indirect methods such as rapid diagnostic DAT (Direct Agglutination Test) and rK39. The disease is confirmed by identifying LD bodies in the bone

1. Assistant Professor of Medicine, Sylhet MAG Osmani Medical College

2. Assistant Professor (Endocrinology), Dhaka Medical College,Dhaka.

3. Master of Biomedicine, MD $2^{\text {nd }}$ part course student, Dhaka Medical College, Dhaka

3. Medicine Specialist, United Hospital.

5. Junior Consultant, Department of Medicine, Shahid Suhrawardi Hospital.

6. Associate Professor of Medicine, Dhaka Medical College.

7. Professor of Medicine, Dhaka Medical College. 
marrow and splenic puncture. To the contrary kalazar lymphadenopathy and finding of $\mathrm{LD}$ bodies in the lympnodes is quite uncommon in the Indian subcontinent, which is a fairly common presentation in African kalazar specially Sudan. ${ }^{2}$ Authors claim to report The first case of lymphatic leishmaniasis in Nepal in $2001^{3}$ though in our search it was revealed that reports of kalaazar lymphadenopathy can be dated, back to 1998 where a 13 year old boy from Dharan, Nepal was reported to be diagnosed with the said. ${ }^{4}$ Lymphadenopathy in kalazar has also been reported in a number of journals in India. In a case report from Iran they found LD bodies from submental lymphnodes of a 9 year old boy. Iran being a country not known to have kalaazar lymphadenopathy inspite of being an endemic area for visceral leishmaniasis; therefor suggested to keep in mind kalaazar as a cause of lymphadenopathy in endemic areas. ${ }^{5}$

In 2007 a Bangladeshi expatriate in Singapore was diagnosed to have kalaazar through bone marrow aspiration, on clinical examination cervical lymphadenopathy was present but no biopsy was taken or FNAC performed as for so it is not possible to differentiate whether the enlargement was due to involvement of the lymphnodes or a reactive change. ${ }^{6}$ We however were unable to find any other case involving Bangladesh or a Bangladeshi individual having been reported for kalaazar lymphadenopathy. The interesting finding of our case is the absence of $\mathrm{LD}$ bodies in the usually expected sites namingly bone marrow and spleen, to the contrary the presence of
LD bodies exclusively in the lymphnodes is quite unique for this region and has opened a new arena to think about.

We therefore suggest keeping in mind kalaazar whenever a patient presents with fever, hepatosplenomegaly and lymphadenopathy in an endemic zone.

\section{References:}

1. Naik SR, Rao PN, Datta DV, et al. Kala-azar in north-western India: a study of 24 patients. Trans Royal Soc Trop Med Hyg 1979; 73:61-65.

2. Siddig M, Ghalib H. Shillington DC, Peterson EA. Visceral leishmaniasis in Sudan: a comparative parasitological method of diagnosis. Trans Roy Soc Trop Med Hyg 1988; 82:66-8.

3. Sharma SK, Das ML, Rijal S, Sah SP, Koirala S. Lymphatic leishmaniasis-first case report from Nepal. Southeast Asian J Trop Med Public Health 2001; 32: 749-50.

4. Kuldeep Singh, Rupa Singh SC. Parija. Lymphadenopathy in a Child with Indian Kala-Azar in Dharan. Nepal Indian Pediatrics 1998;36:11251126 .

5. Baradaranfar MH, Beinesh F. Visceral leishmaniasis (Kala-azar) with a rare manifestation of submental adenopathy MJLRI. 2004; 17: 353355 .

6. Lew J W S, Koh C K, Selvan V S, Shen E. The hunt for an elusive source of pyrexia in a foreign worker: Singapore Med J 2007; 48 : 111. 